\title{
PERSISTING INEQUALITY: A CASE OF PROBABILISTIC DRIVE TOWARDS DIVERGENCE
}

\author{
Robin MAIALEH \\ (Received: 20 February 2016; revision received 11 July 2016; \\ accepted: 12 September 2016)
}

\begin{abstract}
The aim of the study is to prove that agents organised by market forces tend to create and even more so deepen economic disparities over time. Empirical studies do not reliably describe the trend and causes of interpersonal global inequality in recent decades. Hence, the attention is turned to general economic theory with inspiration from Schumpeterian and neoclassical theories. The results indicate that pure market economy logic will tend lead to multi-level divergence.
\end{abstract}

Keywords: perfect competition, inequality, probability, divergence

JEL classification indices: D63, D61, D01, E21

"For whoever has, to him more shall be given, and he will have an abundance; but whoever does not have, even what he has shall be taken away from him."

Mt 13, 12

\section{INTRODUCTION}

Contemporary economic configuration offers numerous pitfalls. One of the most burning and discussed issues is the fact that in spite of steadily increasing global wealth, there are still people without any means to preserve their lives. The goal of the article is to unveil probability-based principles of resource allocation under market conditions, which lead to economic inequalities. The article should help

Robin Maialeh, Assistant Professor at Masaryk Institute Advanced Studies, Czech Technical University in Prague. E-mail: robin.maialeh@berkeley.edu 
us to understand why market rules cannot eliminate inequality; rather, inequality is generated by the rules of the markets. The research thus provides a general analytically-logical principle that can be considered as the engine of inequality in market economies.

Firstly, we depict the state of global inequality based on the Gini coefficient. The subsequent section explains the inclination to the progressively deepening economic inequalities under market conditions. The considered conditions are constituents of the market itself and respect the main principles of the market: profit maximisation and a certain level/form of competition. A theoretical frame of inequality is seen in general questions of creation and appropriation of wealth, which has been broadly described by many current and past critical thinkers. The article applies traditional theoretical frames and methods of mainstream economics, still dominated by Samuelson's neoclassical synthesis. The uniqueness of the article thus lies in employing the methods and thought of orthodox economics, but in the direction of radical political economics. This attitude thus challenges orthodox economics by its own weapon.

Henceforth, we are inspired by growth theories, specifically the Schumpeterian approach of creative destruction and neoclassical theory, which constitute a broader theoretical frame. The latter puts emphasis on savings, which eliminates the Schumpeterian assumption on perfect capital markets, which in theory leads to convergence of economic subjects. On the other hand, Schumpeter developed a method of thinking allowing us to overcome neoclassical stationarity - another fact causing faux convergence of economic subjects.

The article purports to reopen a question of imposing market rules on various fields of public life. For this purpose, general market principles are researched since the contradiction is observed on the very general level. The results indicate that agents interact in the competitive environment, that they are forced by an imperative to maximise their profits, and that they tend to economically diverge. This should warn us against imposing market principles in various fields where inequality is harming our society the most.

\section{DESCRIPTION OF GLOBAL INCOME INEQUALITY}

In this section, we deal with global income inequality from two standpoints. Firstly, we focus on empirical researches based on the Gini coefficient. The section deals with findings on the global interpersonal level. Gini coefficients results are sorted by the method used - purchasing power parities (as the conversion factor for GDP or consumption) and market exchange rates; therefore, the availability of data source was another criterion for adding into the sample. 
We should be aware of the broader environment where research categories are placed. For this purpose, the development of global wealth must be taken into account. Measured by GDP or GDP adjusted per capita, we can observe that in modern history, let us say from the end of World War 2, the pie of global wealth is, with some insignificant stumbles, constantly increasing. This point seems to be crucial - the problem we are facing as a global community is not poverty, which means that there are people of poor living conditions; the problem is that there are people of poor living conditions and, conversely, people of unlimited living conditions at the same time. Therefore, we tackle this phenomenon as an inequality issue. A causality between these two is briefly commented on at the end of the section.

\subsection{Global income inequality by the Gini coefficient}

Most researchers throughout the world agree that global income inequality is high. Estimates and calculations nevertheless exhibit ambiguous results, or at least, there is no simple answer as to whether global inequality is increasing or decreasing. Despite the fact that most papers incline toward increasing inequality, it would require tremendous efforts to conjure highly reliable research on global inequality. Considering the recent and widely discussed works of e.g. Piketty (2014) and Milanovic (2016), we rather focus on the most respected academic papers, which have remarkably contributed to the issue of measuring global income inequality in the recent decades only. The aim is to provide an influential sample of what is the development of inequality.

Let us begin with Cornia - Kiiski (2001) whose research covered $80 \%$ of the world population and $91 \%$ of the world GDP. They claimed that $59 \%$ of the world population lived in countries where inequality is increasing, while only $5 \%$ of the world population lived in countries where inequality is decreasing (2001: 21). The research shows that since the 80 's, there has been a significant increase in inequality in both developing and developed countries.

If we turn our attention directly to the Gini coefficient, these are the results: Dorwick - Akmal (2005) used Deininger - Squire's (1996) data for within-country inequality and GDP PPPs from the Penn World Table (PWT 5.6). The authors argue that the global Gini coefficient decreased from 0.659 in 1980 to 0.636 in 1993 when using standard PPP conversion factors (Geary-Khamis method) for measuring relative incomes. In contrast, by using their own "Afriat" conversion factors, inequality slightly rose from 0.698 to 0.711 . Milanovic (2005) used his own dataset of household surveys for within-country inequality and PWT and World Bank data for PPP. He reports an increasing Gini coefficient from 0.622 to 
Table 1. Global inequality overview

\begin{tabular}{llll}
\hline Author(s) & $\begin{array}{c}\text { Inequality } \\
\text { trend }\end{array}$ & \multicolumn{1}{c}{ Method } & \multicolumn{1}{c}{ Data sources } \\
\hline Dorwick - Ackmal (2005) & decreasing & PPPs (Geary-Khamis) & $\begin{array}{l}\text { Deininger-Squire (1996); } \\
\text { PW.6 5.6 }\end{array}$ \\
\hline Dorwick - Ackmal (2005) & increasing & PPPs (Afriat index) & $\begin{array}{l}\text { Deininger-Squire (1996); own } \\
\text { calculations of Afriat index }\end{array}$ \\
\hline Dorwick - Ackmal (2005) & increasing & market exchange rates & Deininger-Squire (1996) \\
\hline Milanovic (2005) & increasing & PPPs (consumption) & household surveys; PWT; WB \\
\hline Milanovic (2005) & increasing & market exchange rates & household surveys \\
\hline Milanovic (2002) & increasing & market exchange rates & household surveys \\
\hline Milanovic (2002) & increasing & PPPs (consumption) & household surveys; PWT; WB \\
\hline Sala-i-Martín (2006) & decreasing & PPPs & Deininger-Squire (1996); \\
\hline Bhalla (2002) & decreasing & PPPs & OWU-WIDER; PWT 6.0 \\
\hline $\begin{array}{l}\text { Bourguignon - Morrison } \\
\text { (2002) }\end{array}$ & constant & PPPs & own dataset; Maddison (1995) \\
\hline Dikhanov - Ward (2001) & increasing & PPPs (consumption) & Milanovic (2002); WB \\
\hline $\begin{array}{l}\text { Korzeniewicz and Moran } \\
\text { (1997) }\end{array}$ & increasing & market exchange rates & WB \\
\hline & & &
\end{tabular}

0.641 between 1988 and 1998. In his previous work, Milanovic (2002) observed an increase from 0.628 to 0.660 between 1988 and 1993. Sala-i-Martín (2006) used Deininger - Squire's (1996) and UNU-WIDER data for within-country inequality; GDP PPPs from PWT 6.0. Based on these datasets, Sala-i-Martín found a decrease ${ }^{1}$ of the Gini coefficient from 0.660 to 0.637 between 1980 and 2000. Bhalla (2002) used his own data for within-country inequality; as a source of GDP PPPs, he used the World Development Indicators and PWT 5.6. Bhalla recorded a reduction from 0.686 in 1980 to 0.651 in 2000. Bourguignon - Morrison (2002) found no change in the Gini coefficient between 1980 and 1992, which remained at 0.657 . Authors also used their own data for within-country inequality and Maddison's data (1995) for GDP PPPs. Dikhanov - Ward (2001) noted an increase in Gini from 0.683 to 0.668 during the period of 1970-1999. They used Milanovic's (2002) data for within-country inequality and World Bank data for PPPs. It should be noted that Milanovic $(2002,2005)$ and Dikhanov - Ward (2001) calculate PPPs for consumption. ${ }^{2}$

1 Sala-i-Martín contends that countries were converging. However, as he reminds, if we excluded China from the sample, we would get results that sign economic divergence on the interpersonal level. In this particular case, the Gini coefficient would increase from 0.620 to 0.648 , which represents an increase of global interpersonal inequality by $4.4 \%$ (2006:388).

2 For more details on variances in income and consumption inequality, see the well-known study by Krueger - Perri (1995) or the newer study of Aguiar - Bils (2011). 
The results presented above were calculated at PPPs. The second option is to compare national incomes through market exchange rates. Dorwick - Akmal (2005) argue for an increasing Gini from 0.779 to 0.824 between 1980 and 1993. Milanovic (2002) had recorded an increase as well, specifically from 0.782 to 0.805 between 1988 and 1993. Three years later (Milanovic 2005), he presented an increase from 0.778 to 0.794 between 1988 and 1998. Finally, Korzeniewicz - Moran (1997) identified an increase of Gini from 0.749 to 0.796 between 1965 and 1992.

In sum, increasing inequality was detected in recent decades by Milanovic (2002, 2005), Dikhanov - Ward (2001), and Korzeniewicz - Moran (1997). Constant or ambiguously interpreted inequality was detected by Dorwick - Ackmal (2005) and Bourguignon - Morrisson (2002). Decreasing inequality was detected by Sala-i-Martín (2006) and Bhalla (2002). Still, most researchers agree with increasing global inequality since the 1980s.

\subsection{Empirical researches - conclusion}

As shown above, we cannot convincingly determine even the trend of how global interpersonal income inequality developed in recent decades. This is mainly due to contradictory results depending on the used data and adopted methods. On the other hand, all researchers seem to agree that inequalities are generally persisting on a very high level. The most valuable finding is that such a complex and systemic issue as global income inequality can be hardly researched by quantitative methods with a significant level of reliability. The data showing a continuous increase of global GDP does not require any deeper analysis ${ }^{3}$ and they can be interpreted, e.g., by PWT 8.0 or by the updated version 8.1.

In order to fill the gap - a possible causality between economic growth and inequality - we should take a brief look at econometric studies dealing with the issue. To cover the causality alone would require separate research. However, the most influential papers were chosen for this reason (particularly Persson - Tabellini 1994; Gomez - Foot 2003; Aghion et al. 1999; Alesina - Rodrik 1991; Berg - Sachs 1988; Deininger - Squire 1996; Barro 1999; Lundberg - Squire 2003; Anand - Segal 2008; Sala-i-Martín 2006; Minoiu 2007; Schulz 1998, etc.). Some of these studies also influenced the one written by Cingano (2014). Nevertheless, neither of these studies addresses assumed causality. Similarly to the previous case of measuring inequality, there are expectable methodological difficulties -

At least, we do not observe long-run declining tendencies of economic performance in any of the world regions. 
none of the models includes all relevant variables; every author works on different assumptions about included variables, and estimate error or multicollinearity play their roles. To conclude, the majority of authors incline toward "latent" negative causality between growth and inequality. This statement, however, should be taken into account with relatively low explanatory power.

\section{THEORETICAL EXPLANATION OF PROGRESSIVE INCLINATION TOWARD DEEPENING INEQUALITY}

The hitherto cited researches have been placed in the empirical field. The next section attempts to uncover inclinations toward deepening inequality under market conditions in the theoretical field and explains why the inequalities captured above persist. Research on existing literature related to agent-based dynamic modelling has been also conducted. The proposed issue of inequality directed us to the auction theory, therefore the sample includes the well-known study by Cassady (1967) and the newer on by Krishna (2009), as well as Riley - Samuelson (1981) and McAfee - McMillan (1987). Research on the modelling of the macro-environment with microeconomic foundations embraces, e.g., Korotayev et al. (2006) and, more recently, Chytilova - Chytil (2014). In game theory, the research of Camerer (2003) and Baik - Jung (2015) were inspected in particular. On the other hand, however insightful these (and some other) studies are, their authors provide too specific formulations of researched problems. These narrowlydefined models are then hardly transferable to the general theoretical frame not only of inequality, but to the general frame of market forces themselves. In this sense, the present article applies, despite its triviality, an innovative formulation of agents" interaction, and by using a mathematical apparatus, it introduces a new framework of agent-based dynamic modelling.

For this purpose, we make use of Schumpeterian and neoclassical theories whose combination is supposed to serve as a unique multi-level research tool. By using the multi-level research tool, we do not face difficulties concerning particular influences on inequality, e.g. national state policy, global economy constellation, individual preferences, etc. The inequality can thus be explained strictly by general market principles, which are valid for all agents on different levels without exceptions. Moreover, inequality is a dynamic process; therefore we work with non-stationary propensities, combining them with newly formulated inflex point. As it is shown further, the model explains why rational economic agents tend to diverge under market conditions. However, such generality requires that the logical sequence must be well defined - this is the subject of the next section. 


\subsection{Context of the general model}

Only conditions and imperatives which are defining pillars of market economies and which are currently the most influential for researched inequality are taken into account in this section. These are summarised as follows. First of all, we have to understand that the market is a mechanism permanently driven by profit maximisation. The second very important attribute is a certain level/form of competition. The interaction of these two attributes causes that every single agent who is ruled by market forces has to adjust his/her behaviour to them, i.e. maximise profit due to competition pressure. If an agent does not accept these imperatives in the long run, the agent loses his/her competitiveness and the agent is excluded from the given market. Every agent whose reproduction depends on resources from the market thus obeys such rules and agents' behaviour is beyond any preferential ranking. Notwithstanding, in the following argumentation we assume homogeneous preferences in order to depict that individual differences principally do not drive inequality and that divergence is captured even among agents with the same decision-making process. We observe both individuals and companies operating under market conditions. This implies that subsequent modelling can be used at different levels.

In the issue of inequality, we work on the assumption that inequality is in general the result of a certain creation and appropriation of wealth (resources). This process inherently reflects the maximisation of profits and competition forces, and hence it might be inspired by growth theories. Every agent has to grow (maximise his/her profits) in order to keep/enhance competitiveness. Therefore, we assume the Schumpeterian growth theory as the ground theory for modelling. The reason is that the Schumpeterian theory allows capturing an "infinite" growth by the innovation strategies of agents; the so-called theory of "creative destruction". Nonetheless, the Schumpeterian theory assumes loans as the source of innovation. Not only because of the broad literature dedicated to "credit constraints", covered also, for example, by Gomez - Foot (2003) and Aghion et al. (1999), such an assumption should be eliminated, mainly because creditworthiness and imperfectness on capital markets in this case might obscure the pure market mechanism. For this purpose, we employ a neoclassical approach to savings. Hereby, we gain a non-stationary frame in which innovations are the engine of progress, while innovations are supported by agents' own unconsumed resources, not by external resources. At this point, we naturally assume a saving-investment identity, simply because everything which has not been consumed is allocated to strengthen agents' competitiveness - every investment and innovation is understood as strengthening agents' competitiveness - an activity to which agents are forced by competitors. Simply put, under market conditions, every action the agent takes is considered as a way of strengthening his/her position on the market. 
We re-formulate income, consumption, savings, and investment/innovation. By $\tau$, we understand total resources in various forms as the result of both labour and capital (including social) which the agent has before any consumption. Further, $\delta$ is assigned to all resources essential for an agent's reproduction on a given economic level; the lowest costs that ensure the agent's survival on a given market to the next period. $\zeta$ is determined by the difference between $\tau$ and $\delta$. It basically represents how much an agent has at a disposal for competitive struggle after securing his/her reproduction. $\zeta$ is also considered equal to investments (innovations): in Schumpeter's language, we talk about resources dedicated to "new combinations". By this we understand all activities which are supposed to strengthen agents' competitiveness. And finally, $\xi$ represents all scarce appropriable resources on the market - the object of the struggle for their appropriation among agents. $\xi$ is appropriated above already allocated resources, which an agent receives in the next period. Based on that we assume that $\tau_{i t}=\tau_{i t-1} \Leftrightarrow \xi_{i t-1}$ $=0$. Generally, we consider zero-sum distribution of $\xi$, except in the final parts of the paper where a possible division of $\xi$ according to the relative agents' market power is outlined. Naturally, in order to research abstract market forces, we must also assume a perfectly competitive market.

\subsection{Formulation of the general model}

Let us start with the algebraic expression of the already explained relationships. Total resources are the sum of reproductive consumption ${ }^{4}$ and remaining, unconsumed resources for strengthening competitiveness of agent $i$ in time $t$. Then we imply

$$
\tau_{i t}=\delta_{i t}+\zeta_{i t}
$$

Reproductive consumption and unconsumed resources are defined by the level of total resources $\tau_{i t}=\left(\tau_{i t-1}+\xi_{i t-1}\right)$; therefore, their function is interpreted as

$$
\begin{aligned}
& \delta_{i t}=\left(P R O P(\delta)_{i t}\right)\left(\tau_{i t-1}+\xi_{i t-1}\right) \\
& \xi_{i t}=\left(\operatorname{PROP}(\zeta)_{i t}\right)\left(\tau_{i t-1}+\xi_{i t-1}\right)
\end{aligned}
$$

where $P R O P(\delta)$ denotes propensity to consume, measuring dynamised shares of reproductive consumption on changing total resources, and $P R O P(\zeta)$ denotes

$4 \quad$ We are here inspired by Harris who defined necessary consumption as a "quantity required for consumption in order that a unit of labor may be maintained in production" (1978: 55). 
propensity to save, measuring dynamised shares of unconsumed resources on changing total resources. These propensities say what fraction of total resources is dedicated to reproductive consumption and what fraction is left unconsumed for enhancing competitiveness when changing total resources over time. Despite evidence that changes in $\operatorname{PROP}(\delta)$ and $P R O P(\zeta)$ derive from marginal propensities, i.e. from what fraction of additional unit of resources is consumed and what fraction of additional unit is saved for competition in the next period, it is illuminating to define $P R O P(\delta)$ and $P R O P(\zeta)$ as above. It is also clear that dynamised propensities, changing with any additional unit of resources, cannot be defined as average propensities. Propensities change proportionally and inversely, thus

$$
\operatorname{PROP}(\delta)_{i t}+\operatorname{PROP}(\zeta)_{i t}=1
$$

For capturing the process of creation and appropriation of wealth/resources - the process generating inequality - we firstly assume Schumpeterian theory advanced by Aghion - Howitt (2009). Subsequently presented growth theory allows us to reflect market principles of profit maximisation and competition. Economic growth $g_{t}$ (the result of production process) is calculated as follows

$$
g_{t}=\frac{A_{t}-A_{t-1}}{A_{t-1}}
$$

where $A_{t}$ is a technological parameter denoting productivity of inputs in the economy at time $t$. Technological parameter is bigger at $t$ than at $t-1$ because $A_{t-1}$ has changed due to innovations and therefore it evinces higher productivity level represented by $A_{t}$. Then

$$
A_{t}=\gamma A_{t-1} ; \gamma>1
$$

and thus

$$
g_{t}=\gamma-1
$$

For a successful innovation, the agent must conduct an activity with an economic objective; in other words, expend resources in innovation process - in the process of increasing competitiveness. Aghion - Howitt (2009) assume that the more resources the agent expends, the more likely the innovation will be successful and the more likely the agent will generate profit. Therefore, probability $\mu_{t}$ that the innovation is successful at $t$ is positively related to the amount of resources $R_{t}$ allocated to the innovation process. Further, probability $\mu_{t}$ is inversely related to $\gamma A_{t-1}$, which represents a new level of innovation productivity. In other 
words, the higher the level of productivity we assume, the more difficult it is to implement the innovation. The probability is then captured as

$$
\mu_{t}=\phi\left(\frac{R_{t}}{\gamma A_{t-1}}\right)
$$

From the above, we can conclude that the probability of successful innovation increases with the amount of resources the agent is willing/capable of expending on its realisation. At the same time, the probability of implementing a successful innovation decreases the higher the level of productivity the agent strives for. From (8) it is also obvious that the differentiating factors of inequality are the amount or resources $R_{t}$ allocated to the innovation and $\gamma A_{t-1}$ representing the new level of innovation productivity. Assuming a constant $\gamma A_{t-1}$ for all agents, i.e. equal conditions for all agents, we can say that the bigger the amount of unconsumed resources the agent has at $t$, the higher the probability to innovate and to strengthen his/her competitiveness the agent has at $t+1$.

At this point, it is crucial to understand that the amount of resources $R_{t}$ represents the unconsumed resources and investments of the $i$ 's agent. Therefore, we claim that

$$
\zeta_{i t}=R_{i t}
$$

Now we can develop the probabilistic process; to ease the understanding, we employ only two agents, A and B, who compete for resources on a given market. If we assume the homogeneous preferences of agents and $\gamma A_{t-1}=$ const, i.e. identical market conditions for both agents, then probabilities $p_{t}^{A} ; p_{t}^{B}$ to gain additional appropriable resources $\xi$ on the market are given by the relation of the agent's unconsumed resources which he/she has at his/her disposal for the competition struggle. Further, we define the simultaneous moves of agents. By assuming this, we get the following Scheme 1.

Scheme 1 shows that agents $A$ and $B$ start to compete for appropriable resources $\xi_{\tau}$ in time $t$. $A$ 's probability of appropriation $\xi_{\tau}$ is given by the amount of resources $A$ is able to allocate to the competitive struggle $\left(\operatorname{PROP}(\zeta)_{t}^{A} \tau_{t}^{A}\right)$ and the total amount of resources allocated to the competitive struggle; in this particular case, the resources allocated by $A$ and $B$, i.e. $\left(\operatorname{PROP}(\zeta)_{t}^{A}\right) \tau_{t}^{A}+\left(\operatorname{PROP}(\zeta)_{t}^{B}\right) \tau_{t}^{B}$ in time $t$. In $t+1, \xi_{\tau}$ was already distributed and became a part of someone's total resources in $t+1$. If $A$ appropriated $\xi_{\tau}$, then $A$ 's probability of appropriation $\xi_{\tau+1}$ would be higher compared to $B$ 's due to $A$ 's higher numerator $\left(P R O P(\zeta)_{t+1}^{A}\right)\left(\tau_{t}^{A}+\xi_{t}\right)$ compared to $B$ 's $\left(\operatorname{PROP}(\zeta)_{t+1}^{B}\right) \tau_{t}^{B}$. The "probability tree" thus shows that the probability to appropriate additional resources is one-sidedly cumulating over time. 


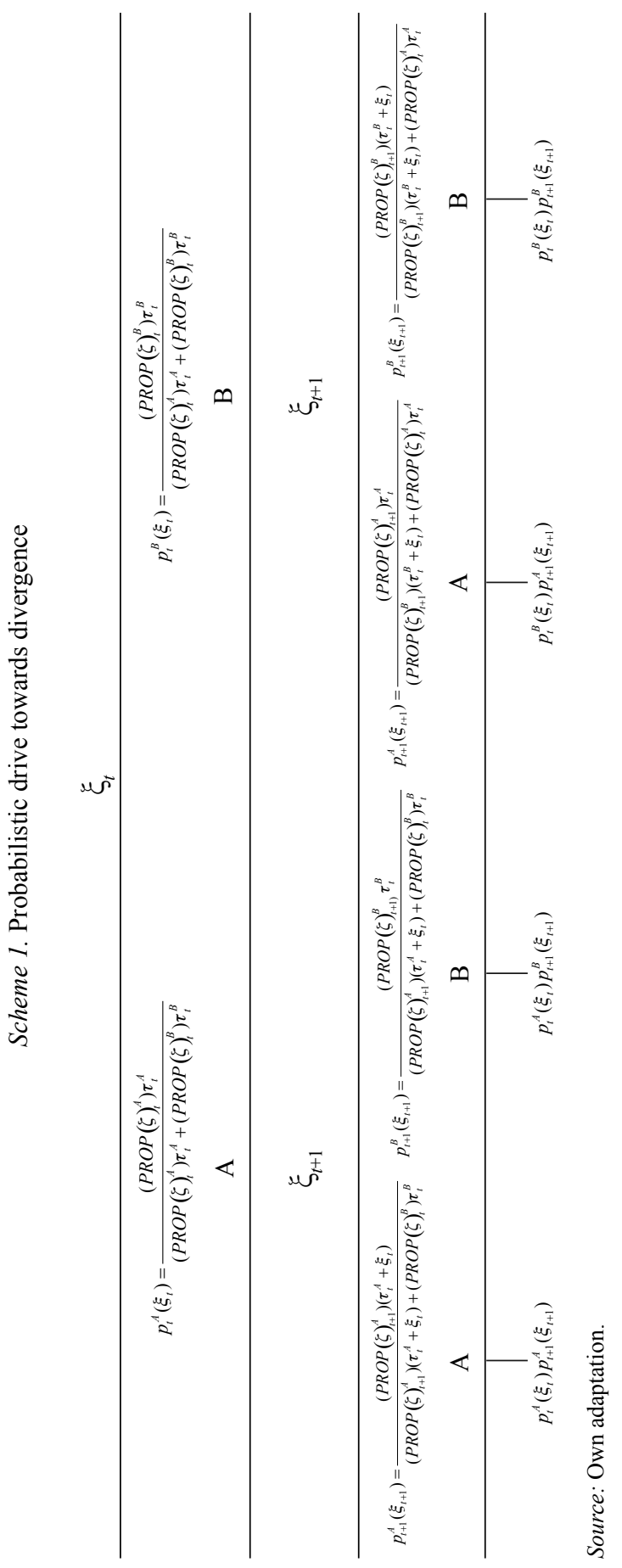


According to the purpose of the paper, we must modify standard explanation of propensities (2) and (3). When we consider a very low level of total resources, let us say $\delta_{i t} \rightarrow \tau_{i t}$, the agent tends to consume all of them. In this case, the propensity to consume is approaching to 1 . It follows that $P R O P(\zeta)$ is approaching to 0 proportionally, as $P R O P(\delta)$ is approaching to 1 . With a higher amount of total resources, the agent assesses which fraction of the resources to consume and which to keep for strengthening his/her position. Keynes claimed that consumption is an increasing function of income; 5 therefore, we re-formulate his thesis as follows

$$
\operatorname{PROP}(\delta)_{i t}=\frac{\partial \delta_{i t}}{\partial \tau_{i t}} ; \operatorname{PROP}(\zeta)_{i t}=\frac{\partial \zeta_{i t}}{\partial \tau_{i t}}
$$

However, an agent consumes a constantly smaller fraction of the additional unit of total resources because an agent saturates constantly less urgent needs; the relative amount (relative to total resources) of what an agent necessarily needs to expend is decreasing, for that

$$
\Delta \delta_{i t} ; \Delta \xi_{i t} \leq \Delta \tau_{i t} ; 0 \leq \frac{\Delta \delta_{i t}}{\Delta \tau_{i t}} ; \frac{\Delta \xi_{i t}}{\Delta \tau_{i t}} \leq
$$

It redirects us to dynamic forms of propensities. The dynamic forms require a formulation of the following conditions for one of the propensities; for an assumed continuous function $\operatorname{PROP}(\zeta):[0, \infty) \rightarrow[0,1)$ we have

$(H)\left\{\begin{array}{c}(\operatorname{PROP}(\zeta))(0)=0 \\ \operatorname{PROP}(\zeta) \text { is increasing }[0, \infty) \\ \lim _{\tau_{i t} \rightarrow \infty}(\operatorname{PROP}(\zeta))\left(\tau_{i t}\right)=1 \\ \exists \varepsilon_{\text {const }} \in(0, \infty): \operatorname{PROP}(\zeta) \text { is convex }\left(0, \varepsilon_{\text {const }}\right) \& ; \operatorname{PROP}(\zeta) \text { is concave }\left(\varepsilon_{\text {const }}, \infty\right)\end{array}\right.$

where $\varepsilon_{\text {const }}$ is an inflex point, which is equal to a certain level of total resources where propensities are equal, respectively have values $=0.5$. An economic interpretation of $\varepsilon_{\text {const }}$ is that for $\left\{\tau_{i t} \mid 0<\tau_{i t}<\varepsilon_{\text {const }}\right\}$ agent $i$ prefers/"is forced" to consume a bigger fraction of the additional unit of total resources than to use it in competition, i.e. $\operatorname{PROP}(\delta)>\operatorname{PROP}(\zeta)$. Inversely, for $\left\{\tau_{i t} \mid \varepsilon_{\text {const }}<\tau_{i t}<\infty\right\}$

5 Despite the statistical estimation of Kuznets (1946:53) and Goldsmith (1955: 47-88) regarding long-run constancy of the propensity to consume, and redefinitions by Duesenberry (1949) and Friedman (1957), the Keynesian version is, at this place, re-formulated in a different sense with the emphasis on the necessity to consume. This helps us keep the consistency. 
agent $i$ prefers/"is allowed" to use in the competitive struggle a bigger fraction of the additional unit of total resources, i.e. $P R O P(\zeta)>P R O P(\delta)$. For instance, when assuming a small amount of total resources, let us say $\delta_{i t} \rightarrow \tau_{i t}$, the agent is inclined to consume all total resources. From this, we deduce that a constantly bigger fraction of additional units of total resources is becoming a component of unconsumed resources. Decreasing propensity to consume or increasing propensity to save when increasing total resources are derived from the relative amount of resources which an agent necessarily needs/is forced to sacrifice - the relative amount decreases with increasing total resources. The absolute amount of resources which an agent necessarily needs to expend naturally increases and reproductive consumption remains to be an increasing function of total resources. Therefore, the focus on the necessity allows us to abstract from stochastic, randomly determined particularities, e.g. geographical, psychological, cultural, political, technological, etc., as well as attributes of the concrete economic environment; for instance, certainty and uncertainty level, which may distort the interpretation in a discourse of general economic theory. ${ }^{6}$

As a general solution can be considered the set of functions $\mathfrak{M}$, which follows $H$ conditions

$$
\mathfrak{M}=\{P R O P(\zeta) \in C([0, \infty),[0,1)) \mid(H) \text { holds }\}
$$

However, in order to provide a concrete function solution, we need a concrete functional form that corresponds to $\mathfrak{M}$, i.e. for which propensities are continuous on $[0, \infty)$ with values $[0,1)$. Therefore, we define propensities as the functions of the hyperbolic tangent of total resources

$$
\operatorname{PROP}(\delta)_{i t}=\frac{1-\tanh \left(\tau_{i t}-\varepsilon_{\text {const }}\right)}{2}
$$

and equivalently the propensity to save

$$
\operatorname{PROP}(\zeta)_{i t}=\frac{\tanh \tanh \left(\tau_{i t}-\varepsilon_{\text {const }}\right)+1}{2}
$$

Outlined above is how to dynamically model a general development of propensities when increasing total resources. Fig. 1 thus depicts that propensities have asymptotic properties; specifically, $\operatorname{PROP}(\delta)$ is limitedly approaching to 0 when increasing total resources, formally described by

6 For equilibrium solutions of various effects on persisting inequality, see, e.g., Durlauf (1992). 


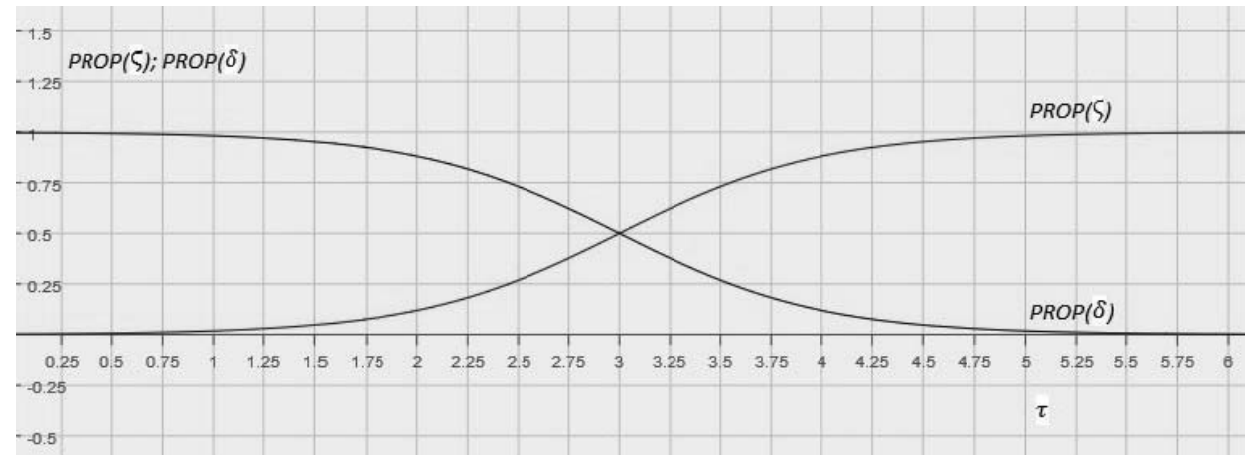

Fig. 1 Development of propensities $P R O P(\zeta)$ and $P R O P(\delta)$ when increasing total resources $\tau$;

$$
\varepsilon_{\text {const }}=\mathbf{3}
$$

Source: Own adaptation.

$$
\lim _{\tau_{i t} \rightarrow \infty} \frac{1-\tanh \left(\tau_{i t}-\varepsilon_{\text {const }}\right)}{2}=0
$$

and equivalently $P R O P(\zeta)$ is limitedly approaching to 1 at the same time

$$
\lim _{\tau_{i t} \rightarrow \infty} \frac{\tanh \tanh \left(\tau_{i t}-\varepsilon_{\text {const }}\right)+1}{2}=1
$$

Agents with a lower amount of total resources then relatively expend a bigger fraction of these resources on consumption, while agents with a higher amount of total resources can afford to keep a bigger fraction of resources unconsumed. One might argue that by this we reformulate and then eliminate one of theoretical determinants of the saving rate (deriving from omitted capital market), i.e. the interest rate. The elimination, however, does not cause a distortion of the theory because interest rate is substituted in a sense of appropriated resources flowing from the successful allocation of unconsumed resources. In other words, deferred consumption is not rewarded by interest rate resulting from savings, but by appropriated resources resulting from unconsumed resources, i.e. investments. In sum, agents with a higher amount of total resources can transform unconsumed resources into investments and build up their competitiveness further.

To provide evidence, we create an equality from (1), (2) and (12), which incorporates the inequality-accelerating effect of dynamised propensities; hence we imply

$$
\frac{1-\tanh \left(\tau_{i t}-\varepsilon_{\text {const }}\right)}{2}=\frac{\tau_{i t}-\zeta_{i t}}{\tau_{i t}}
$$


In order to capture the total resource divergence among agents, the solution for $\tau$ is provided through Lambert's product-log $W$ function

$$
\begin{gathered}
\frac{1}{2}\left[1-\frac{e^{2\left(\tau_{i t}-\varepsilon_{\text {cons }}\right)}-1}{e^{2\left(\tau_{i t}-\varepsilon_{\text {cons }}\right)}+1}\right]=\frac{\tau_{i t}-\zeta_{i t}}{\tau_{i t}} \\
\zeta_{i t}\left(e^{2 \varepsilon_{\text {const }}}+e^{2 \tau_{i t}}\right)=e^{2 \tau_{i t}} \tau_{i t} \\
\tau_{i t}=\zeta_{i t}+\frac{1}{2} W\left(2 e^{2\left(\varepsilon_{\text {cons }}-\zeta_{i t}\right)} \zeta_{i t}\right)
\end{gathered}
$$

The calculation above provides one of possible function solutions which grasps the outlined economic divergence. If we run a simulation of two agents with the same initial levels of total resources, competing on a perfectly competitive market under the same conditions and assuming homogeneous preferences, we would observe, on a certain significance level, steadily diverging amounts of total resources which agents have at a disposal in time $t+n .^{7}$ These findings, due to Schumpeterian heritage, thus oppose the very idea of seeking equilibrium, which provides a unique theoretical approach to the issue. ${ }^{8}$ It also explains why the whole subset of literature is neglected.

Another option is to leave the zero-sum idea in cases where $\xi$ is allowed to be divided among all competitors. To reach a higher preciseness in this regard, we clarify how to cope with appropriable resources through an adjustment which would take into account (8). Hence, we weight appropriable resources as an absolute value with the probability of its realisation $\left(\xi_{i t}^{p}\right)$, which is linked to the intended level of productivity (an increase of competitiveness) and to the relation of unconsumed resources. When assuming $\xi_{i t}=(\gamma-1)$, we deduce

$$
\xi_{i t}^{p}=(\gamma-1) \frac{\sum_{t-z}^{t-1} \zeta_{i}}{\sum_{t-z}^{t-1} \sum_{j=1}^{n} \zeta_{j}}
$$

7 Such calculation can be progressively elaborated by using time inhomogeneous Markov chains. This partly unexplored method could bring a more specified procedure; however, we do not make use of it as it could obscure the central logic of the article.

8 Despite the fact, game theorists will be still be able to define equilibria solutions upon closer specification of the model as a simultaneous, symmetric, non-cooperative strictly competitive (zero-sum) game. This might be complicated for more than two agents and it could lead game theorists into a sequence of auctions with budget constraints. However, we provide a strong recommendation to pay attention to the probabilities of the occurrence of such equilibria solutions. 
where $\sum_{t-z}^{t-1} \zeta_{i}$ denotes sum of all unconsumed resources left for competition of agent $i$ from $t-z$ to $t$, whilst $\sum_{t-z}^{t-1} \sum_{j=1}^{n} \zeta_{j}$ represents all unconsumed resources left for competition of all agents from $t-z$ to $t$, while $t-z$ represents the base period and $t-1$ the last observed period. " $z$ " therefore represents the number of considered time periods.

For a more general expression, we may use findings from asymmetric contests with initial probability of winning, where the contest success function for $i$ 's agent is formulated by Baik - Jung (2015) as follows

$$
p_{i}=\theta \alpha_{i}+(1-\theta) f_{i}(x)
$$

where $p_{i}$ is the final probability of the appropriation of resources on the market, $\theta$ is an exogenous impact parameter, $\alpha_{i}$ is the ianitial probability of gaining resources, and $f_{i}(x)$ represents an additional function which reflects influences on $p_{i}$, except initial probability. In our case, initial probability is considered as the relation of an agent's unconsumed resources and unconsumed resources of all agents over time, i.e. $\frac{\sum_{t-2}^{t-1} \zeta_{i}}{\sum_{t=2}^{t-2} \sum_{j=1}^{n} \zeta_{j}}$.

To conclude, we might say that possible future resource appropriation is the result of today's resource allocation. Inasmuch as the equations depict the interdependency of present and future resources, they simultaneously include, according to the set of assumptions and outlined relationships, inherent inclination to deepen inequalities over time. If we assigned the equation (17) to two identical agents, we would observe a constantly deepening resource gap between the agents. Another characteristic of the equation is the fact that it includes an accelerator, which is based on non-stationary propensities. The dynamised form of propensities accelerates the process of deepening inequality, although it is not the prime stimulus of inequality.

At this time, it should also be noted that we assume pure market conditions, which are, more or less, not present in our space-time. Market conditions are influenced by numerous particularities, from individual preferences to built-in stabilisers on the macro-level, which, inter alia, by definition work against market tendencies. This is therefore one of the reasons why we do not observe such a drive towards inequality. In addition, an agent cannot compete for all appropriable resources on the market, which significantly neutralises diverging tendencies in a broader context. However, the article demonstrates that imposing market principles without corridors could result in increasing the gap between those who lack wealth/opportunities and those who by far do not. The gap in priority areas, for instance in medical care, food production, water management, or education is undoubtedly harming societies all around the world. The question is whether to 
support such market principles, especially if we bear in mind these highly important spheres of democratic society.

The research can be developed further, e.g. in the sense of Phillips (1966) who identified the principle "success breeds success" in the aircraft industry. Additionally, we might find common denominators with Myrdal-Kaldor's cumulative causation. However, all subsequent research will share the core idea that under market conditions, assuming identical conditions for agents with homogeneous preferences, a permanent drive towards divergence will be still embedded in the market logic.

\section{CONCLUSION}

The aim of the study was to prove that agents organised by market forces tend to create and even deepen economic disparities over time. The broad literature on global interpersonal income disparities was examined in order to present contemporary findings in inequality. The results, however, vary according to the used data and adopted methods; hence, we cannot precisely determine the trends in the development of inequality itself. The only aspect all can agree upon is that global inequality is astoundingly high, especially in the context of constantly increasing global wealth - created wealth simply does not contribute to diminishing the gap between the rich and the poor.

We tried to present possible causes of the persistent inequality. Our inspiration arises from the synthesis of Schumpeterian and neoclassical growth theories. The elaborated synthesis shows that agents under market conditions, using their own resources to compete, will diverge according to the probabilities associated with the proportions of their unconsumed resources. Intertemporal asymptotic modification of propensities even accelerates the outlined development - wealthier agents enjoying the same conditions as others will be able to use steadily more resources to defeat the rest within competition. The entire process can be simplified as follows: a higher amount of total resources decreases propensity to consume and increases propensity to save; reproductive consumption is increasing, but slower than unconsumed resources because an increasing fraction of the additional unit of resources is becoming a component of unconsumed resources, which are allocated to build up competitiveness. This consequently increases the probability of further appropriation. Appropriated resources increase total resources in the next period, not just absolutely but relatively to the total resources of other competitors especially, and the cycle continues in the next period - the process refers us to progressively deepening inequalities within pure market rela- 
tionships. The gap between the poor and the rich is then given by probabilities to strengthen their position on the market.

We proved that agents with homogeneous preferences in the same market environment will tend to economically diverge due to underlying market logic. On the other hand, we do not claim that the stronger agents will automatically and always defeat others within competition. The stronger agents will enjoy just the probability-based opportunity to do so. Whether the stronger agents do so or not, depends on the concrete conditions and further specifications of the model. Moreover, there are a number of facts and policies which moderate the process of divergence and thus we are not witnesses of a fast, progressively deepening inequality, at least not in general. Nevertheless, pure market principles combined with the economic rationality of agents will inevitably make inequality worse, at least in these specific terms of economic theory.

Despite the generality of the provided solutions, this paper sufficiently grasps embedded market logic and stays open to modifications for various supporting empirical inequality researches, from, e.g. inter-generational wealth/poverty spillovers to world-systems theories.

\section{REFERENCES}

Aghion, P. - Howitt, P. W. (2009): The Economics of Growth. USA: MIT Press.

Aghion, P. (2002): Schumpeterian Growth Theory and the Dynamics of Income Inequality. Econometrica, 70(3): 855-882.

Aghion, P. - Caroli, E. - Penalosa, G. C. (1999): Inequality and Economic Growth: The Perspective of the New Growth Theories. Journal of Economic Literature, 37(4):1615-1660.

Aghion, P. - Howitt, P. (1992): A Model of Growth through Creative Destruction. Econometrica, 60(2): 323-351.

Aguiar, M. A. - Bils, M. (2011): Has Consumption Inequality Mirrored Income Inequality? NBER Working Paper, No. 16807.

Alesina, A. - Rodrik, D. (1994): Distributive Politics and Economic Growth. Quarterly Journal of Economics, 109(2): 465-490.

Anand, S. - Segal, P. (2008): What Do We Know about Global Income Inequality? Journal of Economic Literature, 46(1): 57-94.

Baik, K. H. - Jung, M. H. (2015): Asymmetric Contests with Initial Probabilities of Winning. Available via DIALOG. http://www.econ.sinica.edu.tw. Cited 12 Nov 2015.

Barro, R. J. (1999): Inequality, Growth and Investment. NBER Working Paper, No. 7038.

Bhalla, S. S. (2002): Imagine There's No Country: Poverty, Inequality, and Growth in the Era of Globalization. Washington, D.C.: Peterson Institute.

Berg, A. - Sachs, J. (1998): The Debt Crisis: Structural Explanations of Country Performance. NBER Working Paper, No. 2607.

Bourguignon, F. - Morrisson, C. (2002): Inequality among World Citizens: 1820-1992. American Economic Review, 92(4): 727-744. 
Camerer, C. F. (2003): Behavioral Game Theory: Experiments in Strategic Interaction. Princeton University Press.

Cassady, R. (1967): Auctions and Auctioneering. University of California Press.

Chytilova, H. - Chytil, Z. (2014): Experimental Macroeconomics Evaluation of Coordination Favorableness at Aggregate Level. Ekonomický časopis, 62(8): 779-804.

Cingano, F. (2014): Trends in Income Inequality and its Impact on Economic Growth. OECD Social, Employment and Migration Working Papers, No. 163.

Cornia, G. A. - Kiiski, S. (2001): Trends in Income Distribution in the Post-World War II Period Evidence and Interpretation. United Nations University, WIDER Discussion Paper, No. 2001/89.

Deninger, K. - Squire, L. (1996): A New Dataset Measuring Income Inequality. World Bank Economic Revue, 10: 565-591.

Dikhanov, Y. - Ward, M. (2001): Evolution of the Global Distribution of Income in 1970-99. Fourth Meeting of the Expert Group on Poverty Statistics, Rio de Janeiro, Brazil.

Dorwick, S. - Akmal, M. (2005): Contradictory Trends in Global Income Inequality: A Tale of Two Biases. Review of Income and Wealth, 51(2): 201-229.

Duesenberry, J. S. (1949): Income, Saving and the Theory of Consumer Behavior. Cambridge: Harvard University Press.

Durlauf, S. N. (1992): A Theory of Persistent Income Inequality. NBER Working Paper, No. 4056.

Friedman, M. (1957): Theory of the Consumption Function. NBER, Princeton University Press.

Goldsmith, R. A. (1955): A Study of Saving in the United States. Vol. 1. Princeton University Press.

Gomez, R. - Foot, D. K. (2003): Age Structure, Income Distribution and Economic Growth. Canadian Public Policy, Supplement: The Linkages between Economic Growth and Inequality, 29: S141-161.

Harris, D. J. (1978): Capital Accumulation and Income Distribution. Stanford University Press.

Korotayev, A. - Malkov, A. - Khaltourina, D. (2006): Introduction to Social Macrodynamics: Compact Macromodels of the World System Growth. Moscow: Editorial URSS Publishers.

Korzeniewicz, R. P. - Moran, T. P. (1997): World-Economic Trends in the Distribution of Income, 1965-1992. American Journal of Sociology, 102(4): 1000-1039.

Krishna, V. (2009): Auction Theory. Second edition. Academic Press.

Krueger, D. - Perri, F. (2005): Does Income Inequality Lead to Consumption Inequality? Evidence and Theory. Center for Financial Studies (CFS), Goethe University Frankfurt, No. 15.

Kuznets, S. (1946): National Income: A Summary of Findings. New York: NBER.

Lundberg, M. - Squire, L. (2003): The Simultaneous Evolution of Growth and Inequality. The Economic Journal, 113(487): 326-344.

Maddison, A. (1995): Monitoring the World Economy: 1820-1992. Paris: OECD Development Centre. Available via DIALOG. http://www.ggdc.net/MADDISON/Monitoring.shtml.

McAfee, R. P. - McMillan, J. (1987): Auctions and Bidding. Journal of Economic Literature, 25(2): 699-738.

Milanovic, B. (2016): Global Inequality: A New Approach for the Age of Globalization. Cambridge: Belknap Press.

Milanovic, B. (2005): Worlds Apart: Measuring International and Global Inequality. Princeton University Press.

Milanovic, B. (2002): True World Income Distribution, 1988 and 1993: First Calculation Based on Household Surveys Alone. Economic Journal, 112(476): 51-92. 
Minoiu, C. (2007): Poverty Analysis Based on Kernel Density Estimates from Grouped Data. Columbia University Institute for Social and Economic Research and Policy, Working Paper, No. 07-07.

Persson, T. - Tabellini, G. (1994): Is Inequality Harmful for Growth? American Economic Review, 84(3): 600-621.

Phillips, A. (1966): Patents, Potential Competition, and Technical Progress. American Economic Review, 56(2): 301-310.

Piketty, T. (2014): Capital in the Twenty-First Century. Cambridge: Belknap Press.

Riley, J. - Samuelson, W. (1981): Optimal Auctions. The American Economic Review, 71(3): 381392.

Sala-i-Martín, X. (2006): The World Distribution of Income: Falling Poverty and...Convergence, Period. The Quarterly Journal of Economics, 121(2): 351-397.

Schulz, T. P. (1998): Inequality in the Distribution of Personal Income in the World: How It Is Changing and Why. Journal of Population Economics, 11(3): 307-344. 